\title{
Nanomatrix Synthesis for Particle Size Characterization by Sol-Gel Technique via Carboxyl Methyl Cellulose Approach: Case Study of Arrinrasho Clay as Potential Pharmaceutical Excipient
}

\author{
Edah, A. $0^{1}$, Kolawole, J. A ${ }^{2}$, Alemika, T. A ${ }^{2}$ \\ ${ }^{1}$ Department of Chemistry, University of Jos, Nigeria. \\ ${ }^{2}$ Department of Pharmaceutical Chemistry, University of Jos, Nigeria. \\ edahalex2005@gmail.com; edaha@unijos.edu.ng
}

\begin{abstract}
In material science, particle size measurement is a key parameter in surface area determination, which plays a central role in reaction rate evaluation especially in drug delivery systems. In this study we seek to employ Carboxyl Methyl Cellulose (CMC) in the preparation of a suitable analyte in the characterization of Arrinrasho clay as potential excipient. A stable sol-gel was generated from a solution of pulverized clay in a matrix of CMC. The sol-gel wet chemical technique is widely used recently in the field of material research especially for catalysts and ceramic engineering. A network of discrete particles assembled in a matrix are captured via XRD and electron scanning microscope for observation. XRF technique was employed in the elemental analysis. The nanomatrix generated in this research is notably safe for handling, it is stable, highly reproducible, the CMC employed is readily available, it is universally cheap and the procedure for preparation is not complicated, hence it is highly recommended for adoption in material assay. Evaluation of the Arrinrasho clays showed that they were not radioactive, the dry powder had a free-flowing nature, it had a light cream to white color in appearance, the particles size had dimension in nanometric regions. Corrosive metals such as Bismuth were absent. Titanium oxide that enhances some cosmetic products was found to be present. These attributes of Arrinrasho clays, makes it suitable for an excipient in certain topical pharmaceutical products.
\end{abstract}

Keywords: Nanomatrix, Sol-gel technique, soft synthesis, Carboxyl Methyl Cellulose, Clay characterization, Pharmaceutical Excipient.

\section{INTRODUCTION}

The soft colloidal chemistry of sol-gel procedure involves two notable phases, the dissolution and the gelation (Sui and Charpentier, 2011). Appropriate handling and sample preparation for instrumental analysis is a vital procedure for the reduction or elimination of the error incurred due to the generation of an analyte for an assay. In this research, our focus is the preparation of a suitable nanomatrix analyte in the characterization of a material such as pulverized Arrinrasho clay by employing Carboxyl Methyl Cellulose (CMC) in a sol-gel technique. Nanomatrix synthesis for the instrumental characterization of materials is an essential step in the use of sol-gel or soft chemical technique (Lee \& Yoo, 2014.,). Generating the matrix is synonymous to a bottom to top approach for obtaining nanoparticles (Hayashi, Suzuki \& Kaneko, 1998). This method is used primarily for the fabrication of materials starting from a chemical solution which acts the precursor for an integrated network of entities presented in a gel-matrix of discrete particles such as clay minerals. A comparative research by Livage et al., did not list $\mathrm{CMC}$ but mentioned triethilphosphate, TEP and Orthorphosphoric acid, $\mathrm{PO}(\mathrm{OH})_{3 .}$ Other important precursors were derived from dissolving $\mathrm{P}_{2} \mathrm{O}_{5}$ in alcohol to form several $\mathrm{PO}(\mathrm{OH})_{3-\mathrm{x}}(\mathrm{OR})_{\mathrm{x}}$ species that have an intermediate reactivity between triethilphosphate Phosphorus Oxychloride or Phosphoric acid. Szu, Lin \& Lin. (1994). used $\mathrm{SiO}_{2}-\mathrm{P}_{2} \mathrm{O}_{5}$ system of Orthorphosphoric acid triethilphosphate and trimethylphospite only 
Nanomatrix Synthesis for Particle Size Characterization by Sol-Gel Technique via Carboxyl Methyl Cellulose Approach: Case Study of Arrinrasho Clay as Potential Pharmaceutical Excipient

as phosphorus precursor. The preparation of mixed oxide catalyst and supported metal-oxide usually involves aqueous phase procedure that may include ion-exchange by impregnation and deposition by precipitation (Védrine, 2019). The huge surface area and high order of entities being sort have been established by Daniel et al, 2012. In the review of nano- $\mathrm{TiO}_{2}$ gel, by Macwan, Dave \& Chaturvedi, 2011, the final application of the gel, implicates the type of synthesis adopted, this is also supported by Puskas et al, 2006., Hayashi, Suzuki \& Kaneko, 1998., Rossetti et al, 2018. This study clearly marks out the use of CMC in the synthesis of a stable and suitable nanomatrix for the purpose of characterization of pulverized materials such as Arrinrasho clays.

\section{Materials AND Method}

The choice of material used in a wet chemical technique of analysis is often associated with the safety measures needed in the handling, stability of the analyte, material disposal where necessary and the reproducibility of the data generated. Sakka \& Kuka, 2005.

\section{Sample Collection}

In February 2015, clay materials at Arrinrasho in Barkin Ladi area within the environs of Jos Plateau state, central Nigeria were collected using suitable high density plastic nonabrasive scooper. The samples were monitored for their alpha- $\alpha$, beta- $\beta$, and gamma- $\gamma$, (gross gamma count) radioactivity, using Gamma scout FCC15 device. The sampled points were located with the aid of a global positioning system that corresponded to the following coordinates and elevations. Latitudes ( $\left.29^{0} 29^{\prime} 19.7^{\prime \prime}\right)$ - ( $\left.09^{\circ} 51^{\prime} 56.4^{\prime \prime}\right)$ at longitudes ( $\left.008^{0} 51^{\prime} 07.3^{\prime \prime}\right)-\left(008^{0} 51^{\prime}\right.$ 05.6") and (4305 - 4590) feet above sea level. Thirty-five (35) samples were obtained in triplicates and coded L25 - L60. The Arrinrasho clay samples were pulverized and kept in zip lock bags in readiness for sol-gel and other procedure.

\section{Reagents, Chemicals and Handy Apparatus}

Analytical grade reagents and chemicals were employed in this study. Carboxyl methyl cellulose (CMC), 2-MethylPropan-1-ol \{Isopropanol (IPA)\}, Sodium hydroxide, Deionized water, phenolphthalein, pH- indicator paper, $50 \mathrm{ml}$ and $100 \mathrm{ml}$ measuring cylinders, $250 \mathrm{ml}$ slim beaker and $500 \mathrm{ml}$ regular beakers, thermometer.

\section{Sample Preparation of Sol-Gel Nanomatrix}

This procedure requires weighing a $0.05 \mathrm{~g}$ portion of pulverized clay sample powder which is dissolved in $100 \mathrm{ml}$ of deionized water. The solution is decanted into a slim $250 \mathrm{ml}$ beaker that would fit into a $500 \mathrm{ml}$ beaker to serve as a jacket. It is worth noting that the transfer procedure was done avoiding the sediments. The beaker is placed on a hot plate and a magnetic bar is introduced to stir the solution without heating at this stage. Using the pH-indicator the neutrality of the 2-Methyl Propanol (IPA) solution is ascertained. The absence of neutrality is corrected in a twostep procedure. First, a few drops of Phenolphthalein indicator solution is added, this is followed by a dropwise addition of dilute Sodium hydroxide solution to obtain the slightest uniform, persistent pink color solution. A $50 \mathrm{ml}$ portion of the neutralized IPA solution is transferred into a $250 \mathrm{ml}$ slim beaker, while stirring. A $1.00 \mathrm{~g}$ portion of the CMC is added and stirring is continued until dissolution is completed. This colloidal solution of CMC/IPA is transferred by using a glass rod in a slanting position into the beaker containing the solution of the clay whose particle size and morphology are to be determined. It is important to note that stirring is maintained in the process even after all the solution is fully homogenized. A syringe is used to introduce $2 \times 5 \mathrm{ml}$ portions of the neutralized IPA, this is targeted at dissolving any lump formed in the dissolution and transfer process. The slim beaker containing the homogenized solution (clay solution + CMC + Neutralized IPA) is placed in a $500 \mathrm{ml}$ beaker containing water. Note that the water level is not allowed to overflow into the slim beaker or out on the hot plate. The stirring process is maintained, while the temperature of the mixture is gradually brought to a range of $(86-90){ }^{\circ} \mathrm{C}$. The gradual evaporation of the IPA from the 
Nanomatrix Synthesis for Particle Size Characterization by Sol-Gel Technique via Carboxyl Methyl Cellulose Approach: Case Study of Arrinrasho Clay as Potential Pharmaceutical Excipient

homogenized solution gives a stable sol-gel matrix, this novel approach generates an analyte which is ready for XRD exposure and particle size determination. The morphology and the elemental content of the samples were evaluated by electron scanning microscope and X-ray fluorescence.

\section{RESULTS AND DiscusSion}

Analyte that are unstable and poorly prepared often generate non-discrete data that are not reproducible and the intrinsic properties of the material under investigation may not be fully ascertained, therefore a good decision for their potential applications may not be optimized. (IPEC, 2010., Levy \& Zayat, 2015). The dissolution and preparation of the nanomatrix from the pulverized clay and the CMC generated a sol-gel with homogeneously dispersed entities in this novel procedure. The stable sol-gel from Carboxyl Methyl Cellulose nanomatrix analyte, consistently gave reproducible data. The particle size, morphology, orientation and their implications are presented on table 1. The mined area is Arrinrasho, the range of particle size observed are between $<100 \mathrm{~nm}-1 \mu \mathrm{m}$ and $\measuredangle 100 \mathrm{~nm}-200 \mathrm{~nm}$. The prominent morphology were regular and irregular hexagons and irregular heptagons. The orientation and common features on display were stacks of sheets accompanied by void spaces. The general remark is that the dimensions were in nanoscale. The elemental content of the Arrinrasho clay samples determined by X-ray florescence techniques are reported on table 2 . This shows that $\mathrm{SiO}_{2}$ and $\mathrm{Al}_{2} \mathrm{O}_{3}$ were (56.21- 58-30) \%

Table1. Evaluation of Particle Size, Morphology, Orientation and Implication

\begin{tabular}{|ll}
\hline Mined Area: & Arrinrasho (I) \& (II) \\
Range of Particle Size dimension: & «100nm - $1 \mu \mathrm{m} ; \ll 100-200 \mathrm{~nm}$ \\
Morphology of Particles: & Regular \& irregular hexagon and irregular heptagon \\
Orientation of Particles \& Features Displayed: & Assembly \& Piles of sheets with notable void spaces \\
Remark: & Observed measurements were in Nano region \\
\hline
\end{tabular}

The mined area was naturally demarcated into I and II by an expanse of unmined land, the particle sizes observed were far lower than $100 \mathrm{~nm}$ as observed in the micrograph. The particle morphology was obvious, displaying regular and irregular shapes. The characteristic void spaces observed were very useful in accounting for the peculiarities, such as adsorption and release of entities exhibited on interacting with the clay materials, Chellan \& Sadler, 2015., Sun \& Xia, 2016., Seisenbaeva et al, 2012., IPEC, 2008.

Table2. Elemental content of Arrinrasho clay samples by X-Ray Fluorescence

\begin{tabular}{|c|c|c|c|c|c|c|}
\hline & $4 \mathrm{~A}$ & $5 \mathrm{~A}$ & $6 \mathrm{~A}$ & $7 \mathrm{~A}$ & $8 \mathrm{~A}$ & $9 \mathrm{~A}$ \\
\hline $\mathrm{SiO}_{2}$ & $58.01 \pm 0.02$ & $62.60 \pm 0.01$ & $60.31 \pm 0.00$ & $56.21 \pm 0.01$ & $58.30 \pm 0.00$ & $31.76 \pm 0.01$ \\
\hline $\mathrm{Al}_{2} \mathrm{O} 3$ & $36.40 \pm 0.00$ & $34.20 \pm 0.00$ & $35.30 \pm 0.00$ & $34.61 \pm 0.00$ & $32.85 \pm 0.01$ & $33.73 \pm 0.01$ \\
\hline $\mathrm{CaO}$ & $0.20 \pm 0.01$ & $0.28 \pm 0.01$ & $0.24 \pm 0.01$ & $0.37 \pm 0.00$ & $0.57 \pm 0.01$ & $0.44 \pm 0.01$ \\
\hline $\mathrm{MnO}$ & ND & ND & ND & $0.01 \pm 0.00$ & ND & $0.01 \pm 0.00$ \\
\hline $\mathrm{TiO}_{2}$ & ND & ND & ND & $0.11 \pm 0.00$ & $0.01 \pm 0.00$ & $0.06 \pm 0.00$ \\
\hline $\mathrm{Fe}_{2} \mathrm{O} 3$ & $3.28 \pm 0.01$ & $1.58 \pm 0.01$ & $2.43 \pm 0.01$ & $0.41 \pm 0.00$ & $1.27 \pm 0.01$ & $0.84 \pm 0.00$ \\
\hline $\mathrm{Cr}_{2} \mathrm{O} 3$ & $0.07 \pm 0.01$ & $0.07 \pm 0.01$ & $0.07 \pm 0.00$ & $0.09 \pm 0.01$ & $0.84 \pm 0.01$ & $0.47 \pm 0.00$ \\
\hline $\mathrm{ZnO}$ & $0.08 \pm 0.00$ & $0.10 \pm 0.00$ & $0.05 \pm 0.00$ & ND & $0.13 \pm 0.00$ & $0.13 \pm 0.00$ \\
\hline $\mathrm{NiO}$ & $0.03 \pm 0.00$ & $0.02 \pm 0.00$ & $0.03 \pm 0.00$ & $0.01 \pm 0.00$ & ND & $0.01 \pm 0.00$ \\
\hline $\mathrm{CuO}$ & $0.04 \pm 0.00$ & ND & $0.04 \pm 0.00$ & $0.03 \pm 0.00$ & $0.06 \pm 0.00$ & $0.46 \pm 0.00$ \\
\hline
\end{tabular}


Nanomatrix Synthesis for Particle Size Characterization by Sol-Gel Technique via Carboxyl Methyl Cellulose Approach: Case Study of Arrinrasho Clay as Potential Pharmaceutical Excipient

The evaluation of the elemental content revealed that the pulverized clay material was rich in Aluminum and Silicon oxides, which constitute the underlying building entities that form the units in the clay minerals, empowering it with special absorptive properties. Gomes et al, 2008. Copper, Nickel, Zinc, Chromium, Iron, Manganese and Calcium are notably present at reasonable concentration. The presence of Titanium oxide in these clay materials is an advantage, it is desirable for certain cosmetic products that glow with white appearance. [CIREP, 2003., IPEC, 2008., Chellan \& Sadler, 2015.]

Table3. Mineral content of Arrinrasho clay by X-ray Diffraction

\begin{tabular}{|l|l|l|}
\hline No. of Composite samples & NMI & SMMP \\
\hline 10 & 13 & $\begin{array}{l}\text { Antigorite, Cristobalite, Dickite-2, Gibbsite, Grunerite, Halloysite, } \\
\text { Halloysite-7, Halloysite-10, Monticellite, Nacrite-2, Riebeckite, } \\
\text { Sepiolite, \& Tobermorite-11A }\end{array}$ \\
\hline $\begin{array}{l}\text { Note: Number of minerals implicated (NMI) Summary of Minerals Most Prevalent in the composite samples } \\
\text { (SMMP) }\end{array}$
\end{tabular}

The identified minerals occur repeatedly in the clay composite samples, the unique properties displayed by each mineral makes it resourceful in a wide range of pharmaceuticals, cosmetics, food and feed products. [JCPDS, 1981., IPEC, 2010., Mourad et al 2009., Vingradov and Anvir, 2014., Todan et al, 2015.]

Table4. Radioactivity Evaluation of Arrinrasho clays by FCC15

\begin{tabular}{|llll|}
\hline Composite samples: & $7 \mathrm{AAG}$ & $8 \mathrm{AAH}$ & $9 \mathrm{AAI}$ \\
Ionizing radiation: & $3.60 \pm 0.01$ & $3.20 \pm 0.01$ & $3.40 \pm 0.01$ \\
Background radiation: & $1.51 \pm 0.01$ & $1.01 \pm 0.01$ & $1.00 \pm 0.00$ \\
The unit of measurement of the radiation is milli Seviet/ year & \\
\hline
\end{tabular}

The ionizing radiation emitted by the clay materials in this research were within acceptable range, their values were notably lower than the $5 \mathrm{mS}$ /year lower limit stipulated by IARC, 2001., CIREP, 2003. and USEPA, 2007, hence making the material safe for handling. This was earlier established by Edah et al, 2012.

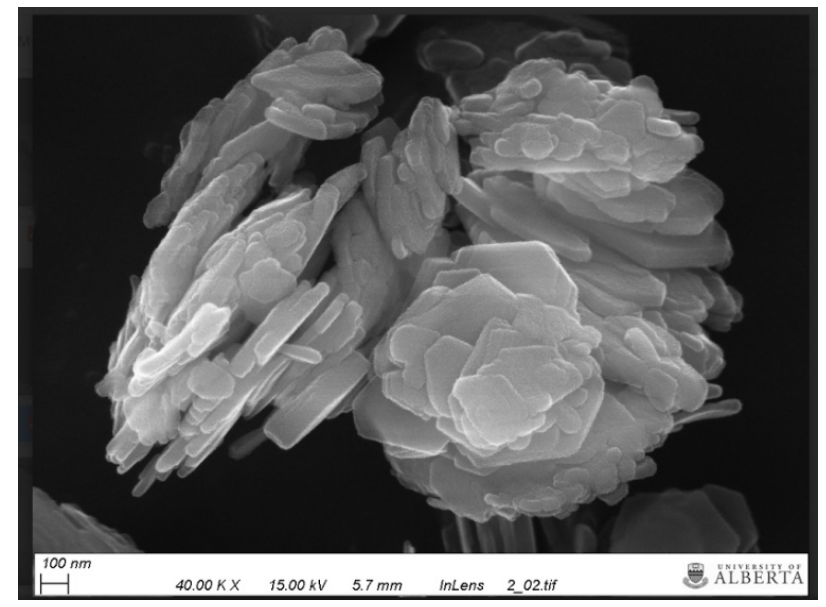

Figure3. SEM micrograph of Arrinrasho clay after CMC sol-gel preparation for particle size evaluation.

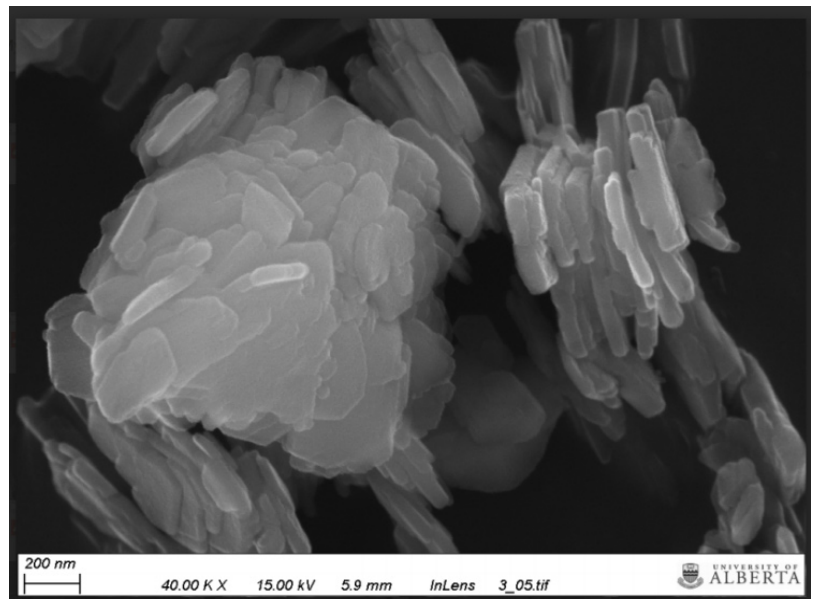

Figure4. SEM micrograph of Arrinrasho clay after sol-gel preparation for particle size evaluation.

Figure $3 \& 4$ are micrographs of images of the Arrinrasho clay minerals as displayed by the SEM at University of Alberta, the unit of measurement is nanometer. The size of the entities, shape and void spaces observed, play 
Nanomatrix Synthesis for Particle Size Characterization by Sol-Gel Technique via Carboxyl Methyl Cellulose Approach: Case Study of Arrinrasho Clay as Potential Pharmaceutical Excipient

a significant role in characterization of the property of these materials. The adsorption, adhesion, slow release properties are some notable extrinsic and intrinsic properties of concern for pharmaceutical consideration. [IPEC, 2008., IPEC, 2010., Gomes et al 2008., Aulton \& Taylor 2013., Todan et al 2015.] The results obtained from the nanomatrix synthesis for particle size characterization by the sol-gel technique using Carboxyl Methyl Cellulose is a novel approach with a case study of Arrinrasho clays, it reveals that results obtained from this procedure are highly reproducible, the error generated due to sample preparation are minimal where elimination is not practicable.

\section{CONCLUSION}

The choice of Carboxyl Methyl Cellulose (CMC) in the synthesis of nanomatrix for sol-gel technique is excellent, this is anchored on the fact that CMC is a very safe material to handle with a standard operating procedure, it yields a stable product that is reproducible, it is readily available, universally cheap to obtain and the procedure for the preparation of the sol-gel nanomatrix is not cumbersome. The properties from the assay of the Arrinrasho clays show that there exist great potentials as excipient with respect to particle size, color, elemental and mineral contents. In view of the aforementioned benefits accruing from this procedure with the use of $\mathrm{CMC}$, we highly recommend this analyte preparatory sequence for techniques that require a stable sol-gel nanomatrix platform for the characterization of materials.

\section{Acknowledgement}

We are highly appreciative of the stewardship of Prof. David Bressler and his research team at the Faculty of Agricultural life and Environmental sciences, University of Alberta, Edmonton Canada for serving as a pillar of support for this work.

\section{REFERENCES}

1. Aulton, M. E., \& Taylor, K (2013. Aulton's Pharmaceutics. The design and manufacture of medicines ( $4^{\text {th }}$ ed.). London: Elsevier Health Sciences Churchill Livingstone.

2. Chellan, P., \& Sadler, P.J (2015) The elements of Life \& medicine, United Kingdom: The Royal Society Publishing.

3. CIREP, (2003) Final report on the safety aluminum silicate, Calcium silicates, Magnesium aluminum silicates, Magnesium silicates Magnesium trisilicate, Sodium magnesium silicate, Zirconium silicate, Attapulgite, Bentonite, Kaolin, Lithium mag, International Journal of Toxicology, 22(1), 37-122.

4. Daniel, G., Nedelec, J.M., Gun'ko, Y.K., Kessler, V.G. High Surface area ordered mesoporous nano-tatinia by a rapid surfactant free approach. J. Mater Chem. 22(2012) pp 20374 - 20380

5. Edah A. O, Kolawole, J. A, Solomon, A.O, Shamle N, \& Awode A.U (2012) Instrumental analysis of Arrinrasho clay for characterization; Journal of Research in Environmental Science \& Toxicology J(2), 019-022.

6. Gomes, C. S., Silva, B. P., Sequeira, M, C \& Gomes, J. H (2008) Potentials for therapeutic purposes of the Biogenic Carbonate Sands occurring in some Islands of the Macaronesia' Archipelago based on their unique chemical \& physical properties, Geochimica Brasiliensis 22(3), 322-343

7. Hayashi, H.; Suzuki, H.; Kaneko, S. Effect of chemical modification on hydrolysis and condensation reaction of zirconium alkoxide. J. Sol-Gel Sci. Technol. 1998, 12, 87-94.

8. IARC (2001) Ionizing radiation, part 2: Some internally deposited radionuclides IARC Monographs on the Evaluation of Carcinogenic Risk to Humans (Vol.78). Lyon: International Agency for Research on Cancer

9. IPEC (2008) Qualification of excipients for Pharmaceutical use; Brussels; The international Pharmaceutical Council. 
Nanomatrix Synthesis for Particle Size Characterization by Sol-Gel Technique via Carboxyl Methyl Cellulose Approach: Case Study of Arrinrasho Clay as Potential Pharmaceutical Excipient

10. IPEC (2010) The IPEC Excipient Stability guide. Geneva: International Pharmaceutical Excipient Council.

11. JCPDS (1980) Powder Diffraction file search mineral for common phases/inorganic and organic, Swarthmore Pennsylvania: Joint Committee for Powder Diffraction Standard USA.

12. Levy, D.; Zayat, M.; The sol-gel Handbook: Synthesis, Characterization and Applications; Wiley-VCH: Weinheim, Germany, 2015.

13. Macwan, D.P., Dave, P.N., Chaturvedi, S. A review on nano-TiO ${ }_{2}$ sol-gel type synthesis and its applications. J. mater. Sci.2011, 46, 3669-3686

14. Mourad, M.C.D., Belov, D.V., Potukhov, A.V., Matthijs de Winter, D.A., Verkleij, A.J. and Lekerkerker, H.N.W. SolGel Transition \& Liquid Crystal Phase Transition in Concentrated Aqueous Suspension of Colloidal Gibbsite Platelets J. Phys. Chem. B, 2009,113(34) 11604

15. Puskas, I.; Fleisch, T.H., Full, P.R.; Kaduk, J.A.; Marshall, C.L., Meyers, B.L. Novel aspects of physical chemistry of $\mathrm{Co} / \mathrm{SiO}_{2}$ Fischer-Tropsch catalyst preparation: The chemistry of cobalt silicate formation during catalyst preparation or hydrogenation. Appl. Catal. A Gen. 2006, 311, 146-154.

16. USEPA (2007) Ionizing Radiation Fact Sheets Series No.2, 15-20.

17. Rossetti, I.; Bonelli, B.; Ramis, G.; Bahadori, E.; Nasi, R.; Aronne, A.; Esposito, S. New insights into the role of the synthesis procedure on the performance of Co-based catalysts for ethanol steam reforming. Top. Catal. $2018,61,1734-1745$.

18. Sakka, S.; Kuka, H. Handbook of Sol-Gel Science and Technology. 1 Sol-Gel processing, $1^{\text {st }}$ ed.; Kluwer Academic publishing: Norwell, MA, USA, 2005.

19. Seisenbaeva, G. A., Daniel, G., Nedelec, J.M., Gun'ko, Y.K. and Kessler, V. G. Solution equilibrium behind the room-temperature Synthesis of Nanocrysalline titanium dioxide. J. mater chem, 2012, 22, 20374.

20. Sun, B., Xia, T. Nanomaterial-Based Vaccine Adjuvants. J. Mater Chem. B. 2016, 4, 5496-5509

21. Sun, B., et al 2017. Enhanced Immune Adjuvant Activity of Aluminum Oxyhydroxide Nanorods through Cationic Surface Functionalization. ACS. Appl. Mater. Interfaces, 2017, 9, 21697-21705. www.acsami.org.

22. Sui, R., Charpentier, P. (2011) Synthesis of metal oxide nanostructure by direct sol-gel chemistry in supercritical fluids. Chem. Rev. 2011, 112, 3057-3082

23. Szu, Sungping., Lin, Chung-Yi. \& Lin, Chung-Hung. (1994) Sol-Gel Prepared Copper Doped SiO2 Glasses. Journal of Sol-Gel Science \& Technology, 2, 881- 884. Kluwer Academic Publisher, Boston. Manufactured in the Netherlands.

24. Todan, L., Anghel, E. M., Osiceanu, P., Turcu, R.V.F., Atkinson, I., Simon, S. and Zaharescu, M. Structural characterization of some sol-gel derived phosphosilicate glasses. J. Mol. Struct. 2015, 1086, 161-171.

25. Vingradov, V.V. and Anvir, D. Low Temperature approach to forming High- Porous Fe (III). j. Mater. Chem. B, $2014,2,2868$.

Citation: Edah, A. 0, Kolawole, J. A, Alemika, T. A, "Nanomatrix Synthesis for Particle Size Characterization by Sol-Gel Technique via Carboxyl Methyl Cellulose Approach: Case Study of Arrinrasho Clay as Potential Pharmaceutical Excipient". American Research Journal of Chemistry, 3(1); pp:1-6.

Copyright (c) 2019 Edah, A. O, Kolawole, J. A, Alemika, T. A, This is an open access article distributed under the Creative Commons Attribution License, which permits unrestricted use, distribution, and reproduction in any medium, provided the original work is properly cited. 